\title{
Clinical Significance of the Prealbumin Level in Gastric Cancer Patients Who Receive Curative Treatment
}

\author{
Toru Aoyama ${ }^{1,2} \cdot$ Masato Nakazono $^{1,2} \cdot$ Kenki Segami $^{1,2} \cdot$ Shinsuke Nagasawa $^{1,2} \cdot$ Kazuki Kano $^{1,2} \cdot$ Kentaro Hara $^{1,2}$. \\ Yukio Maezawa $^{1,2} \cdot$ Itaru Hashimoto $^{1,2} \cdot$ Hideaki Suematsu $^{1,2} \cdot$ Hayato Watanabe $^{1,2} \cdot$ Keisuke Komori $^{1,2}$. \\ Hiroshi Tamagawa ${ }^{1,2} \cdot$ Norio Yukawa $^{1,2} \cdot$ Yasushi Rino $^{1,2} \cdot$ Takashi Ogata $^{2} \cdot$ Takashi Oshima $^{1,2}$
}

Accepted: 29 October 2021

(c) The Author(s) 2021

\begin{abstract}
Background We investigated the clinical influence of the prealbumin level on the gastric cancer survival and recurrence after curative treatment.

Methods This study included 447 patients who underwent curative treatment for gastric cancer between 2013 and 2017. The risk factors for the overall survival (OS) and recurrence-free survival (RFS) were identified.

Results A prealbumin level of $20 \mathrm{mg} / \mathrm{dl}$ was regarded as the optimal point of classification, considering the 3- and 5-year survival rates. The OS rates at 3 and 5 years after surgery were $80.7 \%$ and $65.0 \%$ in the low-prealbumin group, respectively, and $93.1 \%$ and $87.9 \%$ in the high-prealbumin group, respectively, a statistically significant difference $(p<0.001)$. The RFS rates at 3 and 5 years after surgery were $71.7 \%$ and $68.0 \%$ in the low-prealbumin group, respectively, and $90.1 \%$ and $84.7 \%$ in the high-prealbumin group, respectively, a statistically significant difference $(p=0.031)$. A multivariate analysis demonstrated that the prealbumin level was a significant independent risk factor for the OS and RFS. In addition, the rate of introduction of adjuvant chemotherapy was significantly lower and the frequency of peritoneal recurrence and lymph node recurrence significantly higher in the low-prealbumin group than in the high-prealbumin group.

Conclusion Prealbumin is a risk factor for the survival in patients who undergo curative treatment for gastric cancer. It is necessary to develop an effective plan of perioperative care and surgical strategy according to the prealbumin level.
\end{abstract}

Keywords Gastric cancer · Prealbumin · Survival

\section{Introduction}

Gastric cancer is the third-most common cancer and the second leading cause of cancer-related death in the world. Every year, 1 million new cases of gastric cancer occur, with 800,000 gastric cancer deaths noted worldwide [1,2]. Gastrectomy with D2 lymphadenectomy with or without preand/or postoperative adjuvant treatment is a global standard treatment for resectable gastric cancer. However, even when patients receive curative treatment, more than half develop recurrence [3-6]. Once recurrence manifests after curative treatment, the prognosis is limited. Thus, to further improve

Toru Aoyama

t-aoyama@lilac.plala.or.jp

1 Department of Surgery, Yokohama City University, Yokohama, Japan

2 Department of Gastrointestinal Surgery, Kanagawa Cancer Center, Yokohama, Japan patients' chances of a survival, it is necessary to establish new approaches for treatment.

Recently, the preoperative nutritional status was shown to affect the occurrence of postoperative surgical complications, toxicity of adjuvant treatment, and patient's survival in various malignancies [7-10]. Although several scoring system and serum biomarker have been tested, optimal nutritional biomarkers have not yet been established. If physicians could assess optimal serum nutritional biomarker, they might be able to make or change treatment strategies according to those biomarkers.

Prealbumin, a negative acute-phase protein synthesized in the liver, recently became the focus of research as a serum biomarker for assessing the nutritional status [11]. In addition, prealbumin may serve as a more sensitive marker than albumin due to its shorter half-life (about 1.9 days) [12]. Several studies have also reported that prealbumin might be a prognostic factor in patients with lung cancer, esophageal cancer, and renal cell carcinoma [13-15]. However, few studies have assessed the prognostic value of prealbumin in 
gastric cancer patients who have received curative treatment $[16,17]$. In addition, the mechanism underlying the effect of prealbumin on the oncological outcomes in gastric cancer remains unclear.

Therefore, we investigated whether or not the overall survival (OS) and recurrence-free survival (RFS) were affected by the prealbumin level and clarified the clinical course according to the prealbumin level in gastric cancer patients who underwent curative treatment.

\section{Patients and Methods}

\section{Patients}

Patients were selected based on the medical records of consecutive patients who underwent curative resection for gastric cancer at Kanagawa Cancer Center from 2013 to 2017. The inclusion criteria were as follows: (1) histologically proven adenocarcinoma, (2) clinical stage I to III disease as evaluated using according to the 15 th edition of the general rules for gastric cancer published by the Japanese Gastric
Cancer Association [18], and (3) complete (R0) resection of gastric cancer with radical lymph node dissection.

\section{Surgical Procedure and Adjuvant Treatment}

All of the patients received distal or total gastrectomy with lymphadenectomy. D1 + nodal dissection was performed for clinical stage IA disease, while D2 dissection was performed for clinical stage $\geq$ IB. Patients diagnosed with pathological II or III disease received adjuvant chemotherapy for one year. In principle, patients with pathological stage II disease received S-1 monotherapy, while those with pathological stage III disease received S-1 plus docetaxel or capecitabine + oxaliplatin therapy.

\section{Follow-up}

Hematological tests and physical examinations were performed at least every 3 months for five years. The carcinoembryonic antigen and CA19-9 tumor marker levels were checked at least every 3 months for 5 years. Patients underwent computed tomography (CT) every 6-12 months until 5 years after surgery.

Table 1 Patient characteristics

\begin{tabular}{|c|c|c|c|c|}
\hline Characteristics & $\begin{array}{l}\text { No. of patients } \\
(n=447, \%)\end{array}$ & $\begin{array}{l}\text { Low prealbumin } \\
\text { group }(n=78)\end{array}$ & $\begin{array}{l}\text { High prealbumin } \\
\text { group }(n=369)\end{array}$ & $p$ Value \\
\hline Age (years) & & & & 0.075 \\
\hline$<65$ & $135(30.2 \%)$ & $17(21.8 \%)$ & $118(32.0 \%)$ & \\
\hline$\geq 65$ & $312(69.8 \%)$ & $61(88.2 \%)$ & $251(68.0 \%)$ & \\
\hline Gender & & & & $<0.001$ \\
\hline Man & $296(66.2 \%)$ & $29(37.2 \%)$ & $267(72.4 \%)$ & \\
\hline Woman & $151(33.8 \%)$ & $49(62.8 \%)$ & $102(27.6 \%)$ & \\
\hline Pathological type & & & & 0.656 \\
\hline Intestinal & $228(51.0 \%)$ & $38(48.7 \%)$ & $190(51.5 \%)$ & \\
\hline Diffuse & $219(49.0 \%)$ & $40(51.3 \%)$ & $179(48.5 \%)$ & \\
\hline UICC $\mathrm{T}$ status & & & & $<0.001$ \\
\hline $\mathrm{T} 1$ & $276(61.7 \%)$ & $33(42.3 \%)$ & $190(51.5 \%)$ & \\
\hline $\mathrm{T} 2$ to $\mathrm{T} 4$ & $171(38.3 \%)$ & $45(57.7 \%)$ & $126(48.5 \%)$ & \\
\hline Lymph node metastasis & & & & $<0.001$ \\
\hline Negative & $319(71.4 \%)$ & $43(55.1 \%)$ & $276(74.8 \%)$ & \\
\hline Positive & $128(28.6 \%)$ & $35(44.9 \%)$ & $93(25.2 \%)$ & \\
\hline Lymphatic invasion & & & & 0.024 \\
\hline Negative & $141(31.5 \%)$ & $33(42.3 \%)$ & $108(29.3 \%)$ & \\
\hline Positive & $306(68.5 \%)$ & $45(57.7 \%)$ & $261(70.7 \%)$ & \\
\hline Vascular invasion & & & & 0.009 \\
\hline Negative & $193(43.2 \%)$ & $44(56.4 \%)$ & $149(40.4 \%)$ & \\
\hline Positive & $254(56.8 \%)$ & $34(43.6 \%)$ & $220(59.6 \%)$ & \\
\hline Postoperative complications & & & & 0.221 \\
\hline Yes & $66(14.8 \%)$ & $15(19.2 \%)$ & $51(13.8 \%)$ & \\
\hline No & $381(85.2 \%)$ & $63(80.8 \%)$ & $318(86.2 \%)$ & \\
\hline
\end{tabular}

UICC Union for International Cancer Control 


\section{Evaluations and Statistical Analyses}

The significance of differences between the prealbumin levels and clinic pathological parameters was determined using the $\chi^{2}$ test. The Kaplan-Meier method was used to calculate the OS and RFS curves. Univariate and multivariate survival analyses were performed using a Cox proportional hazards model. $P$ values of $<0.05$ were considered to indicate statistical significance. The SPSS software program (v27.0 J Win; SPSS, Chicago, IL, USA) was used for all statistical analyses. This study was approved by the IRB of Kanagawa Cancer Center.

\section{Results}

\section{Patients}

We evaluated 447 patients in the present study. The median age was 68 (range: 32-90) years old, and 296 patients were male, while 151 were female. Based on the 3- and 5-year
OS rate and previous studies, we set the cutoff value for prealbumin at $20 \mathrm{mg} / \mathrm{dl}$ in the present study. When comparing the background characteristics between patients with prealbumin $<20 \mathrm{mg} / \mathrm{dl}$ (low-prealbumin group) and prealbumin $\geq 20 \mathrm{mg} / \mathrm{dl}$ (high-prealbumin group), there were significant differences in the gender and clinical $\mathrm{T}$ and $\mathrm{N}$ status. The incidence rates of female patients and aggressive tumors were much higher in the low-prealbumin group than in the high-prealbumin group (Table 1).

\section{Survival Analyses and Recurrence Patterns}

Each clinicopathological factor was categorized as shown in Table 2 and analyzed for its prognostic significance. Univariate analyses for the OS showed that the pathological $\mathrm{T}$ factor, pathological $\mathrm{N}$ factor, histological type, lymphatic invasion, vascular invasion, and prealbumin level were significant prognostic factors. The prealbumin level was therefore selected for the final multivariate analysis model. The OS rates at 3 and 5 years after surgery were $80.7 \%$ and
Table 2 Uni- and multivariate Cox proportional hazards analysis of clinicopathological factors for overall survival

\begin{tabular}{|c|c|c|c|c|c|c|c|}
\hline \multirow[t]{2}{*}{ Factors } & \multirow[t]{2}{*}{ No } & \multicolumn{3}{|c|}{ Univariate analysis } & \multicolumn{3}{|c|}{ Multivariate analysis } \\
\hline & & OR & $95 \% \mathrm{CI}$ & $p$ Value & OR & $95 \% \mathrm{CI}$ & $p$ Value \\
\hline Age (years) & & & & 0.129 & & & \\
\hline$<65$ & 135 & 1.000 & & & & & \\
\hline $65 \leqq-$ & 312 & 1.561 & $0.879-2.774$ & & & & \\
\hline Gender & & & & 0.209 & & & 0.098 \\
\hline Woman & 151 & 1.000 & & & 1.000 & & \\
\hline Man & 296 & 1.414 & $0.824-2.427$ & & 1.643 & $0.913-2.955$ & \\
\hline Pathological type & & & & 0.049 & & & \\
\hline Intestinal & 228 & 1.000 & & & & & \\
\hline Diffuse & 219 & 1.635 & $1.003-2.666$ & & & & \\
\hline UICC T status & & & & $<0.001$ & & & 0.073 \\
\hline $\mathrm{T} 1$ & 228 & 1.000 & & & 1.000 & & \\
\hline $\mathrm{T} 2-\mathrm{T} 4$ & 219 & 4.518 & $2.675-7.632$ & & 1.816 & $0.946-3.487$ & \\
\hline Lymph node metastasis & & & & $<0.001$ & & & $<0.001$ \\
\hline Negative & 319 & 1.000 & & & 1.000 & & \\
\hline Positive & 128 & 5.203 & $3.166-8.550$ & & 2.939 & $1.618-5.337$ & \\
\hline Pre-albumin level & & & & $<0.001$ & & & 0.002 \\
\hline $20<-$ & 369 & 1.000 & & & 1.000 & & \\
\hline$-<20$ & 78 & 3.045 & $1.839-5.041$ & & 2.375 & $1.362-4.144$ & \\
\hline Lymphatic invasion & & & & $<0.001$ & & & \\
\hline Negative & 141 & 1.000 & & & & & \\
\hline Positive & 306 & 3.072 & $1.896-4.978$ & & & & \\
\hline Vascular invasion & & & & $<0.001$ & & & 0.083 \\
\hline Negative & 193 & 1.000 & & & 1.000 & & \\
\hline Positive & 254 & 4.197 & $2.443-7.210$ & & 1.736 & $0.930-3.238$ & \\
\hline Postoperative complications & & & & 0.843 & & & \\
\hline Yes & 66 & 1.000 & & & & & \\
\hline No & 381 & 1.074 & $0.532-2.167$ & & & & \\
\hline
\end{tabular}

UICC Union for International Cancer Control 


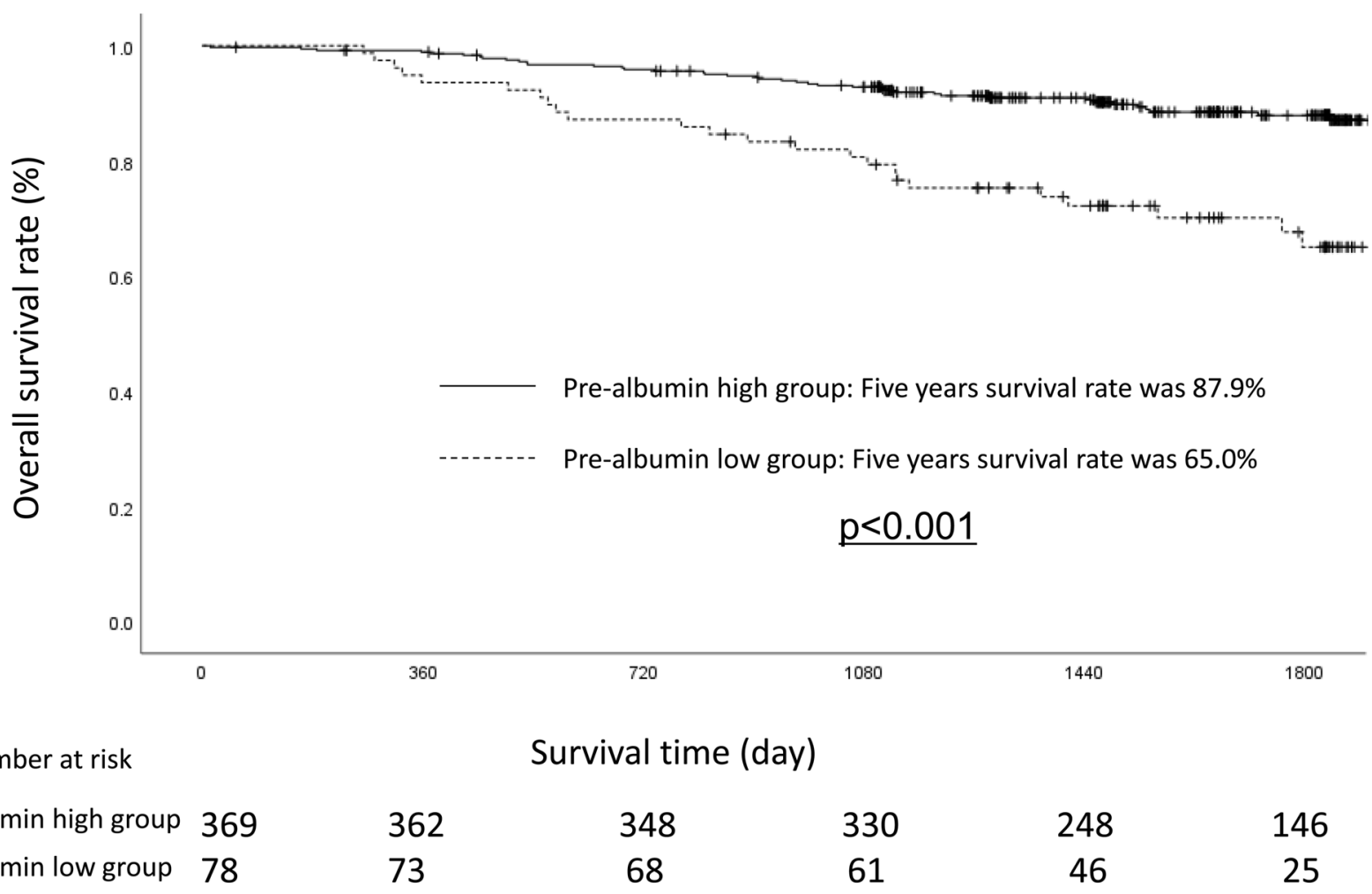

Fig. 1 A comparison of the overall survival in the patients with a prealbumin level of $\geq 20$ versus $<20 \mathrm{mg} / \mathrm{dl}$

$65.0 \%$ in the low-prealbumin group, respectively, and $93.1 \%$ and $87.9 \%$ in the high-prealbumin group, respectively, a statistically significant difference $(p<0.001)$. The OS curves are shown in Fig. 1.

Univariate analyses for the RFS showed that the prealbumin level was a significant prognostic factor. It was thus selected as a significant prognostic factor for the final multivariate analysis model (Table 3). The RFS rates at 3 and 5 years after surgery were $71.7 \%$ and $68.0 \%$ in the low-prealbumin group, respectively, and $90.1 \%$ and $84.7 \%$ in the highprealbumin group, respectively, a statistically significant difference $(p=0.031)$. The RFS curves are shown in Fig. 2 .

\section{Postoperative Adjuvant Chemotherapy Course and Recurrence Patterns in the High- and Low-Prealbumin Groups}

When comparing the postoperative course between the highand low-prealbumin groups, there were some differences in the postoperative adjuvant chemotherapy course. In the present study, $28.0 \%$ (125/447) of patients needed postoperative adjuvant chemotherapy. Among them, 48.7\% (38/78) needed postoperative adjuvant chemotherapy in the low-prealbumin group, while $23.6 \%$ (87/369) needed postoperative adjuvant chemotherapy in the high-prealbumin group, a significant difference $(p<0.001)$.
The introduction rate of postoperative adjuvant chemotherapy differed between the two groups. Among the patients who required postoperative adjuvant chemotherapy, only $71.1 \%$ (27/38) received it in the low-prealbumin group, while $86.2 \%(75 / 87)$ received it in the high-prealbumin group, a significant difference $(p<0.001)$. The site of the first relapse differed significantly between the high- and low-prealbumin groups (Table 4). The incidence of peritoneal recurrence was significantly higher and lymph node metastasis marginally significantly higher in the low-prealbumin group than in the high-prealbumin group.

\section{Discussion}

We evaluated whether or not the preoperative prealbumin level has any clinical significance with regard to the oncological outcomes of gastric cancer patients who receive curative treatment. We found that the patients with a prealbumin level $<20 \mathrm{mg} / \mathrm{dl}$ (low-prealbumin group) had significantly poorer outcomes than those with higher prealbumin levels (high-prealbumin group). In addition, the incidence of the introduction of postoperative adjuvant chemotherapy was significantly lower in the low-prealbumin group than in the high-prealbumin group. Therefore, our results suggest that the preoperative prealbumin level is a promising clinical 
Table 3 Uni- and multivariate Cox proportional hazards analysis of clinicopathological factors for recurrence-free survival

\begin{tabular}{|c|c|c|c|c|c|c|c|}
\hline \multirow[t]{2}{*}{ Factors } & \multirow[t]{2}{*}{ No } & \multicolumn{3}{|c|}{ Univariate analysis } & \multicolumn{3}{|c|}{ Multivariate analysis } \\
\hline & & OR & $95 \% \mathrm{CI}$ & $p$ Value & OR & $95 \% \mathrm{CI}$ & $p$ Value \\
\hline Age (years) & & & & 0.140 & & & \\
\hline$\leq 65$ & 135 & 1.000 & & & & & \\
\hline $65 \leqq-$ & 312 & 1.487 & $0.878-2.518$ & & & & \\
\hline Gender & & & & 0.366 & & & \\
\hline Woman & 151 & 1.000 & & & & & \\
\hline Man & 296 & 1.252 & $0.769-2.036$ & & & & \\
\hline Pathological type & & & & 0.077 & & & \\
\hline Intestinal & 228 & 1.000 & & & & & \\
\hline Diffuse & 219 & 1.500 & $0.957-2.351$ & & & & \\
\hline UICC T status & & & & $<0.001$ & & & 0.010 \\
\hline $\mathrm{T} 1$ & 228 & 1.000 & & & 1.000 & & \\
\hline $\mathrm{T} 2-\mathrm{T} 4$ & 219 & 3.930 & $2.433-6.348$ & & 2.096 & $1.198-3.668$ & \\
\hline Lymph node metastasis & & & & $<0.001$ & & & $<0.001$ \\
\hline Negative & 319 & 1.000 & & & 1.000 & & \\
\hline Positive & 128 & 4.612 & $2.933-7.252$ & & 3.087 & $1.806-5.278$ & \\
\hline Pre-albumin level & & & & $<0.001$ & & & 0.031 \\
\hline $20<-$ & 369 & 1.000 & & & 1.000 & & \\
\hline$-<20$ & 78 & 2.488 & $1.553-4.036$ & & 1.724 & $1.050-2.832$ & \\
\hline Lymphatic invasion & & & & $<0.001$ & & & \\
\hline Negative & 141 & 1.000 & & & & & \\
\hline Positive & 306 & 3.007 & $1.925-4.697$ & & & & \\
\hline Vascular invasion & & & & $<0.001$ & & & \\
\hline Negative & 193 & 1.000 & & & & & \\
\hline Positive & 254 & 3.470 & $2.144-5.617$ & & & & \\
\hline Postoperative complications & & & & 0.992 & & & \\
\hline Yes & 66 & 1.000 & & & & & \\
\hline No & 381 & 1.003 & $0.530-1.899$ & & & & \\
\hline
\end{tabular}

prognostic marker for gastric cancer patients who receive multimodal treatment, and patients with a low prealbumin level require close attention in their postoperative clinical course, especially with regard to adjuvant chemotherapy.

We found that the preoperative prealbumin level was a viable prognostic factor for gastric cancer patients. The hazard ratio (HR) for the OS was 2.375 (95\% confidence interval [CI]: 1.362-4.144), and that for RFS, it was 1.724 (95\% CI: 1.052-2.832). Similar HRs were observed in previous studies. Han et al. evaluated the prognostic impact of preoperative prealbumin in 101 adenocarcinomas of esophagogastric junction (AEG) patients [16]. They set the cut-off value of prealbumin at $200 \mathrm{~g} / \mathrm{l}$ and found that the prealbumin level was indeed a prognostic factor, with a high prealbumin level ( $\geq 200 \mathrm{~g} / \mathrm{l})$ associated the longer OS in AEG patients than a low level. The HR for the OS (prealbu$\min <200 \mathrm{~g} / \mathrm{l}$ for prealbumin $>200 \mathrm{~g} / \mathrm{l}$ ) was 0.494 (95\% CI: $0.271-0.901, p=0.021)$. In addition, Shen et al. evaluated the clinical significance of preoperative prealbumin in 731 stage II and III gastric cancer patients [17] with a cut-off value of $180 \mathrm{mg} / \mathrm{l}$. They found that the preoperative prealbumin level was also a prognostic factor in their study. The median OS was 62 months in the high-prealbumin group and 46 months in the low-prealbumin group (HR: 1.362, 95\% CI: 1.094-1.695), and the median RFS was 61 months in the high-prealbumin group and 37 months in the lowprealbumin group (HR: 1.369, 95\% CI: 1.099-1.706). In both the present and previous studies, a high level of prealbumin demonstrated a positive association with the survival in gastric cancer patients.

However, there remain some concerns associated with the use of the preoperative prealbumin level as a prognostic factor for gastric cancer. First, the optimal cutoff value and method of evaluating the prealbumin level are unclear. In the present study, we set the cutoff value according to the 3- and 5-year survival rates. Han et al. and Shen et al. set their cutoff values using a receiver operating characteristic (ROC) curve analysis based on the most prominent points on the ROC curves $[16,17]$. While the cutoff values have been similar, standard evaluation methods need to be 


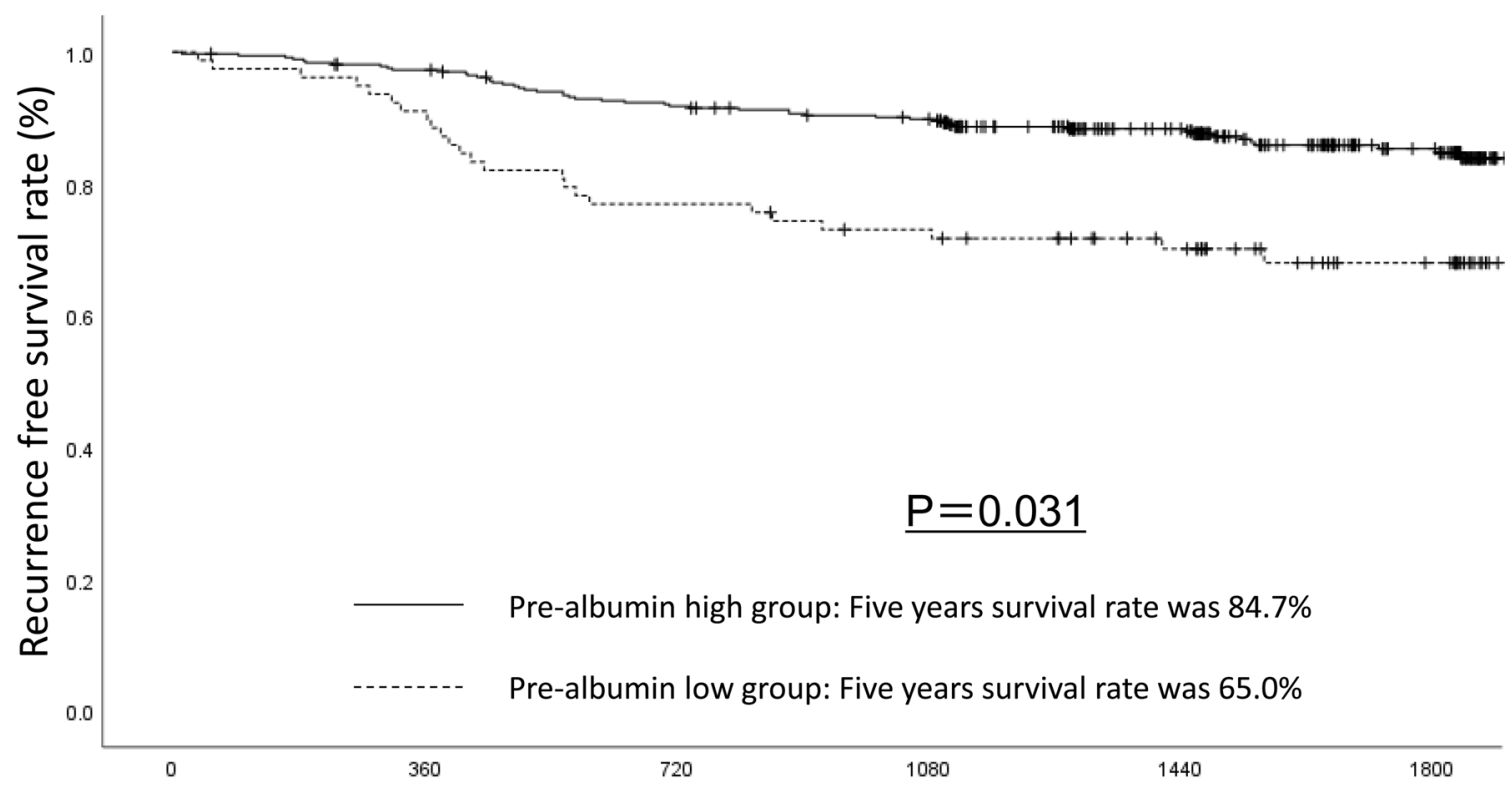

Number at risk

Survival time (day)

$\begin{array}{lllcccc}\text { Pre-albumin high group } & 369 & 356 & 333 & 320 & 243 & 143 \\ \text { Pre-albumin low group } & 78 & 70 & 60 & 55 & 44 & 25\end{array}$

Fig. 2 A comparison of the recurrence-free survival in the patients with a prealbumin level of $\geq 20$ versus $<20 \mathrm{mg} / \mathrm{dl}$

established. Second, the evaluation point of prealbumin is also important. In the present study, we measured the prealbumin level within three to four days before surgery, while the other two studies measured the level within 7 days before surgery. The half-life of prealbumin is about 1.9 days [11, 12]. Thus, the timing of the evaluation of prealbumin might affect the cutoff value. A further analysis is needed to confirm the utility of prealbumin as a prognostic factor in daily clinical practice.

We also found that the prealbumin level influenced the introduction of postoperative adjuvant chemotherapy and recurrence pattern. In the low-prealbumin group, almost half of the patients needed postoperative adjuvant chemotherapy, with $70 \%$ of them actually receiving adjuvant chemotherapy. In contrast, in the high-prealbumin group, only $20 \%$ of the patients needed postoperative adjuvant chemotherapy, with nearly $90 \%$ of them actually receiving adjuvant chemotherapy. Therefore, the merits of adjuvant chemotherapy were limited in the low-prealbumin group. In addition, the difference in the rate of the introduction of adjuvant chemotherapy affected the recurrence pattern. Peritoneal recurrence was significantly more frequent, and lymph node metastasis was marginally more frequent in the low-prealbumin group than in the high-prealbumin group. Several previous pivotal studies showed similar results. For example, the ACTSGC trial, which assessed the usefulness and efficacy of S-1
Table 4 Patterns of recurrence between the patients with prealbumin level $\leq 20$ and those with prealbumin level $20 \leq$ -

\begin{tabular}{|c|c|c|c|c|c|c|c|}
\hline \multirow[b]{3}{*}{ Recurrence site } & \multirow[b]{2}{*}{$\begin{array}{l}\text { All cases } \\
(n=447)\end{array}$} & & \multicolumn{4}{|c|}{ Prealbumin level } & \\
\hline & & & \multicolumn{2}{|l|}{$\begin{array}{l}\leq 20 \\
(n=78)\end{array}$} & \multicolumn{2}{|l|}{$\begin{array}{l}20 \leq- \\
(n=369)\end{array}$} & \\
\hline & Number & $\%$ & Number & $\%$ & Number & $\%$ & $p$ Value \\
\hline Peritoneal & 22 & $4.9 \%$ & 8 & $10.3 \%$ & 14 & $3.8 \%$ & 0.017 \\
\hline Hematological & 15 & $3.4 \%$ & 4 & $5.1 \%$ & 11 & $3.0 \%$ & 0.339 \\
\hline Lymph node & 10 & $2.2 \%$ & 4 & $5.1 \%$ & 6 & $1.6 \%$ & 0.057 \\
\hline Local site & 8 & $1.8 \%$ & 3 & $3.8 \%$ & 5 & $1.4 \%$ & 0.132 \\
\hline Total & 45 & & 19 & & 26 & & \\
\hline
\end{tabular}


adjuvant chemotherapy for locally advanced gastric cancer, demonstrated that effective adjuvant chemotherapy significantly suppressed and reduced peritoneal and lymph node recurrence [19]. The recurrence rates at the peritoneum and lymph node were $11.2 \%$ and $5.1 \%$, respectively, in the adjuvant treatment group and $15.8 \%$ and $8.7 \%$, respectively, in the surgery alone group in the ACTS-GC trial $(p=0.009$ and $p=0.01$, respectively). Given these previous findings, the prealbumin level was considered to have affected the rate of introduction of adjuvant chemotherapy, and this decreased rate of chemotherapy introduction affected the pattern of recurrence and resulted in a poor prognosis.

Several limitations associated with the present study warrant mention. First, the present study was retrospective in nature and conducted at a single center, and the sample size was relatively small. Second, there was some degree of selection bias. In our institution, the surgical indication was determined by seven physicians, including an anesthesiologist, who took into consideration the activities of daily living, performance status, medical history, physical examination findings, and organ function, as is done in general community hospitals. However, there is a possibility that only patients with a good status were selected, as our hospital is a regional cancer center that treats only cancer patients. Elderly patients with co-morbidities who visit general hospitals often undergo surgery at the hospital at which they were diagnosed with gastric cancer. Indeed, the ASA physical status, incidence of co-morbidities, and preoperative laboratory values were lower than in general hospital patients. Therefore, the gastric cancer patients in the present study were well selected and fit for surgery. Considering these limitations, the findings of our study should be validated in another cohort.

In conclusion, prealbumin was determined to be a useful risk factor for the survival in patients who undergo curative treatment for gastric cancer. It is necessary to develop an effective plan of perioperative care and perioperative treatment strategy according to the prealbumin level.

\begin{abstract}
Author Contribution TA and MN made substantial contributions to the concept and design. TA, MN, KS, SN, HS, KK, TY, IH, HW, MN, HT, TO, NY, TO, and YR made substantial contributions to the acquisition of data and the analysis and interpretation of data. TA, HW, MN, HT, TO, NY, and YR were involved in drafting the article or revising it critically for important intellectual content. TA, NM, KK, and TO gave their final approval of the version to be published.
\end{abstract}

Funding This work was supported by JSPS KAKENHI Grant Number $21 \mathrm{~K} 08688$.

\section{Declarations}

Conflict of Interest The authors declare no competing interests.
Open Access This article is licensed under a Creative Commons Attribution 4.0 International License, which permits use, sharing, adaptation, distribution and reproduction in any medium or format, as long as you give appropriate credit to the original author(s) and the source, provide a link to the Creative Commons licence, and indicate if changes were made. The images or other third party material in this article are included in the article's Creative Commons licence, unless indicated otherwise in a credit line to the material. If material is not included in the article's Creative Commons licence and your intended use is not permitted by statutory regulation or exceeds the permitted use, you will need to obtain permission directly from the copyright holder. To view a copy of this licence, visit http://creativecommons.org/licenses/by/4.0/.

\section{References}

1. Bray F, Ferlay J, Soerjomataram I, Siegel RL, Torre LA, Jemal A. Global cancer statistics 2018: GLOBOCAN estimates of incidence and mortality worldwide for 36 cancers in 185 countries. CA Cancer J Clin. 2018;68:394-424. https://doi.org/10.3322/caac. 21492 (PMID: 30207593).

2. Smyth EC, Nilsson M, Grabsch HI, van Grieken NC, Lordick F. Gastric cancer. Lancet. 2020;396:635-48. https://doi.org/10.1016/ S0140-6736(20)31288-5 (PMID: 32861308).

3. Pentheroudakis G, ESMO Guidelines Committee. Recent eUpdates to the ESMO Clinical Practice Guidelines on hepatocellular carcinoma, cancer of the pancreas, soft tissue and visceral sarcomas, cancer of the prostate and gastric cancer. Ann Oncol. 2019;30:1395-7. https://doi.org/10.1093/annonc/mdz180 PMID: 31168599.

4. NCCN. NCCN Clinical Practice Guidelines in Oncology. https:// www.nccn.org/professionals/physician_gls/default.aspx

5. Japanese Gastric Cancer Association. Japanese classification of gastric carcinoma: 3rd English edition. Gastric Cancer. 14: 101-12, 2011. PMID: 21573743. https://doi.org/10.1007/ s10120-011-0041-5.

6. Muro K, Van Cutsem E, Narita Y, Pentheroudakis G, Baba E, Li J, Ryu MH, Zamaniah WIW, Yong WP, Yeh KH, Kato K, Lu Z, Cho BC, Nor IM, Ng M, Chen LT, Nakajima TE, Shitara K, Kawakami H, Tsushima T, Yoshino T, Lordick F, Martinelli E, Smyth EC, Arnold D, Minami H, Tabernero J, Douillard JY. PanAsian adapted ESMO clinical practice guidelines for the management of patients with metastatic gastric cancer: a JSMO-ESMO initiative endorsed by CSCO, KSMO, MOS, SSO and TOS. Ann Oncol. 2019;30:19-33. https://doi.org/10.1093/annonc/mdy502 PMID: 30475956.

7. Shimoda Y, Fujikawa H, Komori K, Watanabe H, Kano K, Yamada T, Shiozawa M, Morinaga S, Katsumata K, Tsuchida A, Ogata T, Oshima T. Preoperative utility of the Glasgow Prognostic Score on outcomes of patients with locally advanced gastric cancer. J Gastrointest Cancer. 2021. https://doi.org/10.1007/ s12029-021-00584-3 (PMID: 33460001).

8. Wang N, Xi W, Lu S, Jiang J, Wang C, Zhu Z, Yan C, Liu J, Zhang J. A novel inflammatory-nutritional prognostic scoring system for stage III gastric cancer patients with radical gastrectomy followed by adjuvant chemotherapy. Front Oncol. 2021;11:650562. https://doi.org/10.3389/fonc.2021.650562 (PMID: 34195071).

9. Inoue H, Kosuga T, Kubota T, Konishi H, Shiozaki A, Okamoto K, Fujiwara H, Otsuji E. Significance of a preoperative systemic immune-inflammation index as a predictor of postoperative survival outcomes in gastric cancer. World J Surg Oncol. 2021;19:173. https://doi.org/10.1186/s12957-021-02286-3 (PMID: 34118953). 
10. Zhang X, Fang H, Zeng Z, Zhang K, Lin Z, Deng G, Deng W, Guan L, Wei X, Li X, Jiang L, Xu L. Preoperative prognostic nutrition index as a prognostic indicator of survival in elderly patients undergoing gastric cancer surgery. Cancer Manag Res. 2021;13:5263-73. https://doi.org/10.2147/CMAR.S316437 (PMID: 34239325).

11. Keller U. Nutritional laboratory markers in malnutrition. J Clin Med. 2019;31(8):775. PMID: 31159248. https://doi.org/10.3390/ jem8060775.

12. Raiten DJ, Sakr Ashour FA, Ross AC, Meydani SN, Dawson HD, Stephensen CB, Brabin BJ, Suchdev PS, van Ommen B, INSPIRE Consultative Group. Inflammation and Nutritional Science for Programs/Policies and Interpretation of Research Evidence (INSPIRE). 2015;145:1039S-108S. Epub 2015 Apr 1. PMID: 25833893. https://doi.org/10.3945/jn.114.194571.

13. Kawai $\mathrm{H}$, Ota $\mathrm{H}$. Low perioperative serum prealbumin predicts early recurrence after curative pulmonary resection for nonsmall-cell lung cancer. World J Surg. 2012;36:2853-7. PMID: 22948197. https://doi.org/10.1007/s00268-012-1766-y.

14. Kelly P, Paulin F, Lamont D, Baker L, Clearly S, Exon D, Thompson A. Pre-treatment plasma proteomic markers associated with survival in oesophageal cancer. Br J Cancer. 2012;106(5):955-61. https://doi. org/10.1038/bjc.2012.15 (PMID: 22294182).

15. Cai W, Kong W, Dong B, Zhang J, Chen Y, Xue W, Huang Y, Zhou L, Huang J. Pretreatment serum prealbumin as an independent prognostic indicator in patients with metastatic renal cell carcinoma using tyrosine kinase inhibit. Clin Genitourin Cancer. 2017;15:e437-46. https://doi.org/10.1016/j.clgc.2017.01.008 (PMID: 28188047).

16. Han WX, Chen ZM, Wei ZJ, Xu AM. Preoperative pre-albumin predicts prognosis of patients after gastrectomy for adenocarcinoma of esophagogastric junction. World J Surg Oncol. 2016;14:279. https:// doi.org/10.1186/s12957-016-1035-x (PMID: 27809860).

17. Shen Q, Liu W, Quan H, Pan S, Li S, Zhou T, Ouyang Y, Xiao H. Prealbumin and lymphocyte-based prognostic score, a new tool for predicting long-term survival after curative resection of stage II/III gastric cancer. Br J Nutr. 2018;120:1359-69. https://doi.org/ 10.1017/S0007114518002854 (PMID: 30370885).

18. Japanese Gastric Cancer Association. Japanese classification of gastric carcinoma: 3rd English edition. Gastric Cancer. 2011;14:101-12. PMID: 21573743. https://doi.org/10.1007/ s10120-011-0041-5.

19. Sakuramoto S, Sasako M, Yamaguchi T, Kinoshita T, Fujii M, Nashimoto A, Furukawa H, Nakajima T, Ohashi Y, Imamura H, Higashino M, Yamamura Y, Kurita A, Arai K, ACTS-GC Group. Adjuvant chemotherapy for gastric cancer with S-1, an oral fluoropyrimidine. N Engl J Med. 2007;357:1810-20. https://doi.org/ 10.1056/NEJMoa072252.

Publisher's Note Springer Nature remains neutral with regard to jurisdictional claims in published maps and institutional affiliations. 